\title{
Balloon Expulsion Test Does Not Seem to Be Useful for Screening or Exclusion of Dyssynergic Defecation as a Single Test
}

\author{
Jooyoung Lee, Kyoung Sup Hong, ${ }^{*}$ Joo Sung Kim, and Hyun Chae Jung \\ Department of Internal Medicine and Liver Research Institute, Seoul National University College of Medicine, Seoul, Korea
}

\section{Background/Aims}

Balloon expulsion test (BET) is regarded as a screening tool of dyssynergic defecation (DD). However, some patients with normal BET results may be treated effectively by biofeedback training. This study aims to validate BET as a single screening test.

\section{Methods}

Two hundred and thirty-two patients who were diagnosed with functional constipation or irritable bowel syndrome with constipation who underwent anorectal manometry (ARM) and BET at Seoul National University Hospital were enrolled. We evaluated the validity of BET based on ARM and electromyography (EMG) during biofeedback training.

\section{Results}

If $\mathrm{BET} \leq 1$ minute was defined as normal, sensitivity and negative predictive value (NPV) of BET in predicting paradoxical contraction based on ARM findings were $71.4 \%$ and $13.9 \%$. If BET $\leq 3$ minutes was defined as normal, sensitivity and NPV were $35.2 \%$ and $6.6 \%$. Specificity and positive predictive value (PPV) of BET $\leq 3$ minutes criteria were $84.8 \%$ and $93.3 \%$. Same analysis was conducted in 107 patients who underwent EMG during biofeedback training. With 1-minute criteria, sensitivity and NPV of BET were $70.3 \%$ and $14.3 \%$. With 3 minutes criteria, sensitivity and NPV of BET was $38.6 \%$ and $8.8 \%$. Specificity and positive predictive values were both $100.0 \%$.

\section{Conclusions}

Based on either ARM or EMG during biofeedback training, sensitivity was at most $71.4 \%$ and NPV was less than $15.0 \%$ irrespective of whether BET was within 1 minute or within 3 minutes. BET seems to have a limitation as both a screening test for dyssynergic defecation and a simple assessment to rule out the necessity of biofeedback training.

(J Neurogastroenterol Motil 2017;23:446-452)

\section{Key Words}

Biofeedback; Constipation; Defecation; Manometry

Received: September 20, 2016 Revised: April 2, 2017 Accepted: April 16, 2017

(.) This is an Open Access article distributed under the terms of the Creative Commons Attribution Non-Commercial License (http://creativecommons. org/licenses/by-nc/4.0) which permits unrestricted non-commercial use, distribution, and reproduction in any medium, provided the original work is properly cited.

${ }^{*}$ Correspondence: Kyoung Sup Hong, MD, PhD Department of Internal Medicine and Liver Research Institute, Seoul National University College of Medicine, Seoul National University Hospital, 101 Daehak-ro, Jongno-gu, Seoul 03080, Korea Tel: +82-2-2072-0360, Fax: +82-2-762-9662, E-mail: kshong1@snu.ac.kr 


\section{Introduction}

Dyssynergic defecation is a common cause of chronic constipation. ${ }^{1}$ The etiology of dyssynergic defecation is unclear, but excessive straining to expel hard stools over time may also lead to dyssynergic defecation. ${ }^{2}$ Most patients with dyssynergic defecation do not respond well to laxatives, but biofeedback training works well for them compared with patients with other types of constipation. Therefore, screening of dyssynergic defecation with accuracy and giving appropriate treatment are important. ${ }^{3}$

To diagnose dyssynergic defecation, changes in pressure in the rectum and anal sphincter muscles during attempted defecation are measured by using anorectal manometry (ARM). ARM is essential for a diagnosis of dyssynergic defecation. ${ }^{1}$ Normally, when a subject bears down or attempts to defecate, there is a rise in rectal pressure, which is synchronized with a relaxation of the external anal sphincter. ${ }^{4}$ However, patients with dyssynergic defecation demonstrate either paradoxical anal contraction or inability to relax the anal sphincter or puborectalis muscles during attempted defecation. ${ }^{4,5}$

The balloon expulsion test (BET) is regarded as a screening tool of dyssynergic defecation in addition to ARM. The BET is easily performed and inexpensive. Therefore, it is widely used at primary care facilities. ${ }^{6}$ A study reported that a diagnosis of dyssynergic defecation with the BET showed a high negative predictive value (NPV) of $97 \%$, suggesting that when BET results were normal, dyssynergic defecation could be excluded. ${ }^{7}$ However, another study reported a contradictory finding which indicated that normal results of BET do not necessarily exclude dyssynergic defecation by demonstrating that some patients with dyssynergic defecation were able to expel the balloon within 1 minute. ${ }^{8}$ Currently BET within 1 minute is regarded as normal, but there is still no consensus on the standard criteria among experts. ${ }^{9}$ Furthermore, some of patients who showed normal BET result can be treated effectively by biofeedback training.

The aim of this study was to conduct a comparative analysis of the results of the BET, ARM, and electromyography (EMG) during biofeedback training and to validate BET as a single screening test.

\section{Materials and Methods}

\section{Study Design and Subjects}

This is a retrospective study conducted on patients who visited the Functional Gastrointestinal Disorders Clinic at Seoul National University Hospital between December 2012 and November 2014. We included patients with functional constipation diagnosed by the Rome III criteria who did not respond to more than 30 days of conventional laxative treatment. We also included patients who were diagnosed with irritable bowel syndrome with constipation (IBS-C) because it has been reported that an overlap of dyssynergic defecation and IBS-C is commonly present. ${ }^{10,11}$ All of the included patients underwent the BET and ARM at the Motility Testing Laboratory within the Gastrointestinal Endoscopy Center of the Seoul National University Hospital. The exclusion criteria were the following: (1) inflammatory bowel disease, (2) history of gastrointestinal surgery, (3) use of drugs that may cause constipation, eg, analgesics, antidepressants, etc, (4) diagnosis of systemic disease, neurological disorders, or mental disorders which may be related to constipation, and (5) anorectal structural abnormality such as rectoceles, rectal prolapse, and intussusception.

Some of all included patients underwent EMG during biofeedback training. Biofeedback training was administered to people who had a willingness to treat, and the time and money to spend on biofeedback training.

The BET, ARM, and EMG during biofeedback training results were reviewed and demographic data including age, sex, and medication history of laxatives were obtained.

\section{Balloon Expulsion Test}

A balloon attached to an anorectal 8-channel catheter (Mui scientific, Ontario, Canada) was inserted into the patients' lower rectum, after which the balloon was filled with $50 \mathrm{~mL}$ of warm water, and the patients were asked to expel it. Before the test, patients were asked to lie down in the left lateral decubitus position with the knees and hip flexed at a $90^{\circ}$ angle, and then a catheter lubricated with jelly was carefully inserted into the rectum. After the balloon was inflated, patients moved to a toilet seat and tried to expel the balloon in a sitting position. BET results were grouped into categories depending on expulsion time. Analysis was performed for each case of 1 minute as the normal criteria and 3 minutes as the normal criteria.

\section{Anorectal Manometry}

The patient lied in the lateral position. ARM was performed using electric manometric perfusion pump (Mui scientific) and the station pull through method was used. The pressure changes in the rectum and anus were recorded by injecting distilled water at a rate of $0.5 \mathrm{~mL}$ per minute using an 8-channel radial measuring tube with 8 sockets spirally spaced $0.5 \mathrm{~cm}$ apart. In addition, a balloon 
catheter with a $3 \times 6 \mathrm{~cm}$ latex balloon at the end of the tube was used to obtain a rectal sensory volume and a threshold value for causing rectoanal inhibitory reflex. Rectal pressure and internal anal sphincter pressure was measured during attempted defecation. Elevation of rectal pressure over $40 \mathrm{mmHg}$ and relaxation of internal anal sphincter pressure over $20 \%$ from baseline were considered as normal. ${ }^{12-14}$

\section{Electromyography During Biofeedback Training}

Biofeedback training was carried out using the surface EMG method using a visual biofeedback system (Regain 2.0; SRS Medical Systems, Inc., Redmond, WA, USA) and internal anal sensors (SenseRx, SRS medical Systems, Redmond, WA, USA). Electrodes were attached to the lower abdomen and an acryl plug was inserted into the anal canal. A distinct, not gradual, increase in EMG activity during bearing down/attempted defecation that was greater than $20.0 \%$ above resting EMG levels was defined as a paradoxical contraction.

\section{Statistical Methods}

We made a diagnosis based on interviews conducted during patient examination and reviewed patients' records. The results of the BET, ARM, and EMG during biofeedback training were also examined by reviewing medical records. Student's $t$ test was used to compare the test results, and the Chi-square test was used for comparison. The similarity in the results was measured with tau statistics, and statistical significance was determined for $P<0.05$ and statistical analysis was performed by using SPSS 23 (IBM Corp, Armonk, NY, USA).

\section{Ethical Considerations}

This study was approved by the Institutional Review Board of Seoul National University Hospital and was conducted in accordance with the Declaration of Helsinki.

\section{Results}

Based on the inclusion and exclusion criteria, 232 patients were included in this study. The mean age of patients was 61.3 years old, and 104 males and 128 females were included. The median followup period was 19.4 months. Of the 232 patients, 227 were taking

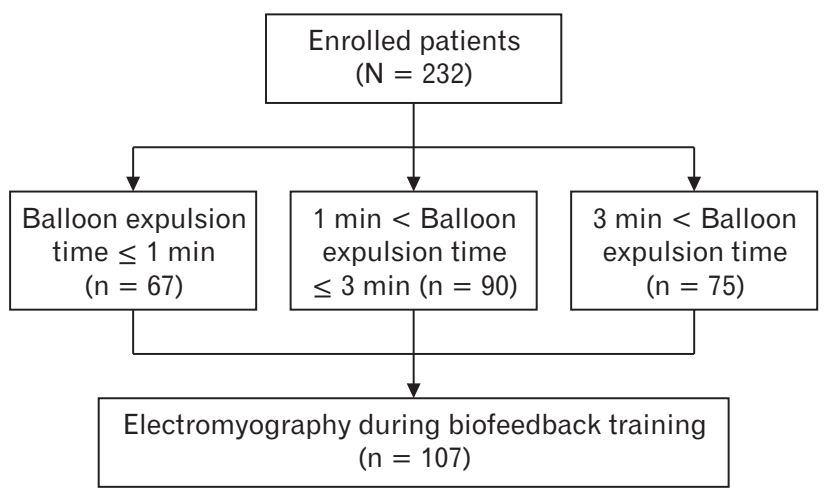

Figure. Flow chart of study design.

Table 1. Baseline Characteristics According to Balloon Expulsion Test Results

\begin{tabular}{|c|c|c|c|c|c|c|}
\hline & \multicolumn{3}{|c|}{ BET (1-minute criteria) } & \multicolumn{3}{|c|}{ BET (3-minute criteria) } \\
\hline & $\begin{array}{l}\text { Normal } \\
(\mathrm{n}=67)\end{array}$ & $\begin{array}{l}\text { Abnormal } \\
(\mathrm{n}=165)\end{array}$ & $P$-value & $\begin{array}{c}\text { Normal } \\
(\mathrm{n}=157)\end{array}$ & $\begin{array}{c}\text { Abnormal } \\
(\mathrm{n}=75)\end{array}$ & $P$-value \\
\hline Gender (male/female) & $23 / 44$ & $81 / 84$ & 0.043 & $63 / 94$ & $41 / 34$ & 0.048 \\
\hline Age (yr) & $60.0 \pm 14.5$ & $64.4 \pm 1.2$ & 0.033 & $59.0 \pm 15.0$ & $62.3 \pm 13.8$ & 0.096 \\
\hline Duration of laxatives use (mo) & $18.0 \pm 13.9$ & $20.0 \pm 13.3$ & 0.310 & $19.8 \pm 12.9$ & $18.7 \pm 14.7$ & 0.589 \\
\hline \multicolumn{7}{|l|}{ Symptoms } \\
\hline Anal pain (yes/no) & $8 / 59$ & $14 / 151$ & 0.46 & $16 / 141$ & $6 / 69$ & 0.811 \\
\hline Incontinence (yes/no) & $16 / 51$ & $41 / 124$ & 0.51 & $40 / 117$ & $17 / 58$ & 0.745 \\
\hline Straining (yes/no) & $3 / 64$ & $154 / 11$ & 0.385 & $147 / 10$ & $71 / 4$ & 1.000 \\
\hline Hard stool (yes/no) & $50 / 17$ & $113 / 52$ & 0.429 & $106 / 51$ & $57 / 18$ & 0.220 \\
\hline Incomplete sensation (yes/no) & $32 / 35$ & $95 / 70$ & 0.192 & $73 / 84$ & $54 / 21$ & $<0.001$ \\
\hline Obstruction (yes/no) & $15 / 52$ & $52 / 113$ & 0.201 & $44 / 113$ & $23 / 52$ & 0.757 \\
\hline Manual maneuver (yes/no) & $9 / 57$ & $22 / 143$ & 1.000 & $20 / 137$ & $11 / 64$ & 0.684 \\
\hline$<3$ times per week, defecation (yes/no) & $19 / 48$ & $49 / 116$ & 0.875 & $43 / 114$ & $25 / 50$ & 0.359 \\
\hline
\end{tabular}

BET, balloon expulsion test. 
laxatives, and the mean number of laxatives used was 2.8.

All patients underwent BET and ARM. On BET, 67 and 90 patients expelled the balloon within 1 minute and between 1 and 3 minutes, respectively. The remaining 75 patients expelled the balloon after more than 3 minutes (Figure). There were no significant differences of symptoms related to defecation according to the BET results (Table 1). Among the several symptoms, 57 patients of all included patients complained of fecal incontinence as a combined symptom of constipation. These patients with fecal incontinence tended to have significantly lower resting pressures $(40.36 \pm 21.8$ $\mathrm{mmHg}$ vs $54.8 \pm 21.7 \mathrm{mmHg}, P<0.01)$ and squeezing pressures $(186.9 \pm 95.3 \mathrm{mmHg}$ vs $213.3 \pm 80.4 \mathrm{mmHg}, P=0.041)$ than patients who did not have fecal incontinence. The rate of patients with low anal tone was higher in patients with fecal incontinence than those without ( $33.0 \%$ vs $10.8 \%, P=0.010$ ).

Of the total of 232 patients, 107 patients were tested for EMG during biofeedback training. There was no statistically significant difference in BET and ARM results between the EMG group and the non-EMG group (Table 2).

\section{Balloon Expulsion Test Results and Anorectal Manometry Findings}

Among 232 patients, 199 patients showed incomplete relaxation or paradoxical contraction of anal sphincter on ARM, while 33 patients showed normal findings. Table 3 shows the concordance between results of BET and presence of paradoxical contraction on ARM. If balloon expulsion within 1 minute was defined as normal, sensitivity and NPV of BET for predicting dyssynergic pattern of anal sphincter were $71.4 \%$ and $14.9 \%$, respectively. Specificity and positive predictive values (PPV) were $30.3 \%$ and $86.1 \%$ (Table 4). If balloon expulsion within 3 minutes was also defined as normal, sensitivity and NPV were $35.2 \%$ and $17.8 \%$, respectively. Specificity and PPV were $84.8 \%$ and $93.3 \%$, respectively (Table 4).

Of 232 patients, 71 patients showed inadequate propulsive force (ie. decreased or insufficiently elevated of rectal pressure), whereas 161 patients showed increases in rectal pressure in the normal range (Table 3). If balloon expulsion within 1 minute was defined as normal, the sensitivity, specificity, PPV, and NPV of BET for predicting inadequate propulsive force, which was deter-

Table 2. Anorectal Manometric Findings of Electromyography Group and Non-electromyography Group

\begin{tabular}{lccc}
\hline & EMG group (n=107) & Non-EMG group $(\mathrm{n}=125)$ & $P$-value \\
\hline Resting pressure $(\mathrm{mmHg})$ & $53.3 \pm 20.9$ & $49.7 \pm 23.8$ & 0.233 \\
Squeezing pressure (mmHg) & $208.9 \pm 76.2$ & $205.3 \pm 91.2$ & 0.745 \\
Sustained duration (sec) & $33.8 \pm 14.0$ & $33.7 \pm 14.4$ & 0.971 \\
Minimal volume (mL) & $35.3 \pm 19.5$ & $39.8 \pm 27.9$ & 0.168 \\
Urgency volume (mL) & $108.2 \pm 52.3$ & $112.7 \pm 53.0$ & 0.518 \\
Maximal volume (mL) & $165.3 \pm 64.8$ & $174.3 \pm 62.9$ & 0.289 \\
Bearing down rectal pressure (mmHg) & $74.3 \pm 39.2$ & $78.1 \pm 49.3$ & 0.535 \\
Bearing down anal sphincter pressure (mmHg) & $85.2 \pm 59.5$ & $73.1 \pm 45.3$ & 0.081 \\
Defecation index & $1.2 \pm 1.1$ & $1.4 \pm 1.1$ & 0.255 \\
\hline
\end{tabular}

EMG, electromyography.

Table 3. Concordance Between Balloon Expulsion Test and Anorectal Manometry Results

\begin{tabular}{|c|c|c|c|c|c|c|}
\hline \multirow[b]{2}{*}{ BET (min) } & \multicolumn{3}{|c|}{ Anal sphincter contraction during attempted defecation } & \multicolumn{3}{|c|}{ Rectal pressure during attempted defecation } \\
\hline & $\begin{array}{l}\text { Normal } \\
\text { relaxation }\end{array}$ & $\begin{array}{l}\text { Paradoxical contraction } \\
\text { or }<20 \% \text { relaxation }\end{array}$ & Total & $\begin{array}{l}\text { Normal } \\
\text { elevation }\end{array}$ & $\begin{array}{l}\text { Decreased or insufficiently } \\
\text { elevated rectal pressure }\end{array}$ & Total \\
\hline$\leq 1$ & 10 & 57 & 67 & 44 & 23 & 67 \\
\hline $1<\mathrm{BET} \leq 2$ & 2 & 11 & 13 & 7 & 6 & 13 \\
\hline $2<\mathrm{BET} \leq 3$ & 16 & 61 & 77 & 60 & 17 & 77 \\
\hline$>3$ & 5 & 70 & 75 & 50 & 25 & 75 \\
\hline Total & 33 & 199 & 232 & 161 & 71 & 232 \\
\hline
\end{tabular}

BET, balloon expulsion test. 
Table 4. Validity of Balloon Expulsion Test Based on Anorectal Manometry and Electromyography Findings

\begin{tabular}{|c|c|c|c|c|}
\hline & $\begin{array}{c}\text { ARM } \\
\text { (paradoxical contraction } \\
\text { or incomplete relaxation) }\end{array}$ & $\begin{array}{l}\text { ARM } \\
\text { (inadequate propulsive force) }\end{array}$ & $\begin{array}{c}\text { ARM } \\
\text { (total findings) }\end{array}$ & $\begin{array}{c}\text { EMG } \\
\text { (paradoxical contraction) }\end{array}$ \\
\hline \multicolumn{5}{|c|}{ BET (1-minute criteria) } \\
\hline Sensitivity (\%) & 71.4 & 72.8 & 66.1 & 70.3 \\
\hline Specificity (\%) & 30.3 & 35.4 & 27.9 & 83.3 \\
\hline $\mathrm{PPV}(\%)$ & 86.1 & 81.2 & 24.9 & 98.6 \\
\hline $\mathrm{NPV}(\%)$ & 14.9 & 25.4 & 68.9 & 14.3 \\
\hline \multicolumn{5}{|c|}{ BET (3-minute criteria) } \\
\hline Sensitivity (\%) & 35.2 & 37.1 & 37.1 & 38.6 \\
\hline Specificity (\%) & 84.8 & 69.4 & 69.4 & 100 \\
\hline $\operatorname{PPV}(\%)$ & 93.3 & 30.7 & 30.7 & 100 \\
\hline NPV (\%) & 17.8 & 75.2 & 75.2 & 8.8 \\
\hline
\end{tabular}

ARM, anorectal manometry; EMG, electromyography; BET, balloon expulsion test; PPV, positive predictive value; NPV, negative predictive value.

mined by using ARM, were $72.8 \%, 35.4 \%, 81.2 \%$, and $25.4 \%$, respectively (Table 4 ). If balloon expulsion within 3 minutes was also defined as normal, the sensitivity, specificity, PPV, and NPV of BET were $37.1 \%, 69.4 \%, 30.7 \%$, and $75.2 \%$, respectively (Table 4).

We also analyzed the sensitivity, specificity, PPV, and NPV of BET compared with total ARM findings (based on paradoxical contraction and insufficient increase of rectal pressure). If balloon expulsion within 1 minute was defined as normal, sensitivity and $\mathrm{NPV}$ of BET for predicting functional defecation disorder were $66.1 \%$ and $68.9 \%$, respectively. Specificity and PPV were $27.9 \%$ and $24.9 \%$, respectively (Table 4 ). If balloon expulsion within 3 minutes was also defined as normal, sensitivity and NPV were $37.1 \%$ and $75.2 \%$, respectively. Specificity and PPV were $69.4 \%$ and $30.7 \%$, respectively (Table 4 ).

\section{Balloon Expulsion Test Results and Electromyography During Biofeedback Training}

Analysis was also conducted in 107 patients who underwent EMG during biofeedback training. The average number of biofeedback training was 4.3 sessions. The presence or absence of paradoxical contraction in the EMG was determined in the first session of biofeedback training. One hundred and one patients showed paradoxical anal contraction, whereas 6 patients showed normal anal contraction. Concordance between time-to-balloon expulsion and the EMG results regarding anal sphincter contraction was observed with tau-b $=0.253(P=0.005$; Table 5$)$. If balloon expulsion within 1 minute was defined as normal, the sensitivity, and NPV of BET in predicting paradoxical contraction shown were $70.3 \%$ and $14.3 \%$, respectively. Specificity and PPV were $83.3 \%$ and $98.6 \%$, respectively (Table 5 ). In contrast, if balloon expulsion
Table 5. Concordance Between Balloon Expulsion Test and Electromyography During Biofeedback Training

\begin{tabular}{lccr}
\hline & \multicolumn{3}{c}{ EMG, anal sphincter } \\
\cline { 2 - 4 } BET $($ min $)$ & $\begin{array}{c}\text { Normal } \\
\text { relaxation }\end{array}$ & $\begin{array}{c}\text { Paradoxical } \\
\text { contraction }\end{array}$ & Total \\
\hline$\leq 1$ & 5 & 30 & 35 \\
$1<\mathrm{BET} \leq 2$ & 1 & 4 & 5 \\
$2<\mathrm{BET} \leq 3$ & 0 & 28 & 28 \\
$>3$ & 0 & 39 & 39 \\
Total & 6 & 101 & 107 \\
\hline
\end{tabular}

EMG, electromyography; BET, balloon expulsion test.

within 3 minutes was defined as normal, the sensitivity, and NPV of BET was $38.6 \%$ and $8.8 \%$, respectively. Specificity and PPV were both $100 \%$ (Table 4).

\section{Discussion}

The BET is simple and easy to perform, and its effectiveness as a screening tool to diagnose dyssynergic defecation has been demonstrated in several studies. ${ }^{8}$ However, in the clinical setting, some patients present dyssynergic movement of the anal sphincter or puborectalis muscles during simulated defecation training, although their BET results are normal. In the present study, among the 107 patients who received biofeedback training, 33 patients showed improvement of their symptoms during defecation and paradoxical anal contraction during EMG on biofeedback training. Among the 33 patients, 8 patients expelled the balloon within 1 minute and 16 patients expelled the balloon within 3 minutes. Thus, we re-evaluat- 
ed the significance of BET in diagnosing patients with dyssynergic defecation.

Recently, several studies have adopted balloon expulsion within 1 minute as the criteria to define normal results on BET. ${ }^{15-18}$ However, in the present study, the sensitivity of BET with the 1-minute criteria was not high enough to predict dyssynergic defecation comparison based on ARM or EMG during biofeedback training. With the 3 minutes criteria, sensitivity was even lower. Thus, although the 1 minute criteria may be more significant than the 3 minutes criteria, unlike the previous studies, BET seems to have a limitation as a screening test for dyssynergic defecation.

The NPV of BET was $14.0 \%$ and $17.8 \%$ with 1 minute and 3 minutes as the normal criteria, respectively, which was very low. Thus, even if BET is normal, dyssynergic defecation cannot be excluded. Therefore, based on BET as a single test, disregarding dyssynergic defecation or exclusion of the necessity of biofeedback training seems to be unreasonable. According to the 3 minutes criteria of BET based on ARM and EMG during biofeedback training, PPVs were $93 \%$ and $100 \%$, respectively. This result could mean that patients who cannot expel the balloon within 3 minutes may have dyssynergic defecation.

The reason why our results are different with the results of previous studies that reported high NPV and sensitivity of BET might be the inclusion of patients who complain of fecal incontinence as a combined symptom of constipation. Patients with fecal incontinence secondary to fecal impaction were reported to demonstrate impaired balloon expulsion. ${ }^{19,20}$

In another literature, $86 \%$ of patients with fecal incontinence have little difficulty with balloon expulsion. ${ }^{20,21}$ A study showed $92 \%$ of patients with fecal incontinence could expel the balloon and the mean expulsion time was 50 seconds. ${ }^{22}$ In the present study, 57 patients of all included patients complained of fecal incontinence as a combined symptom of constipation. Sixty-one percent of the patients with combined fecal incontinence could expel the balloon within 1 minute, but were diagnosed with dyssynergic defecation according to ARM or EMG during biofeedback training. These findings suggest that a substantial proportion of constipated patients with fecal incontinence might show false negative results of BET.

A previous study argued that 2 minutes would be an appropriate upper limit in the BET. ${ }^{23}$ However, in the present study, the portion of patients who expelled the balloon between 1 and 2 minutes after insertion was only $5 \%$. Therefore, the 2 minute criteria do not seem to change results significantly.

Among 107 patients who received biofeedback training based on EMG, 39 exceeded 3 minutes in expelling the balloon, and all of them showed paradoxical contraction of the anal sphincter on EMG. Several reasons why the BET predicted EMG results during biofeedback training more accurately than ARM could be suggested. First, it has to do with different patient postures for $\mathrm{ARM}$ and for EMG taken during biofeedback training. EMG is performed in the sitting position, whereas ARM is performed in the left lateral decubitus position. A study reported that an assessment of bowel movements could be made most appropriately in the sitting position. ${ }^{24}$

This study has several limitations. First, only $46 \%$ of the total patients received biofeedback training with EMG. This study performed through a retrospective analysis of data from routine clinical practices in a single tertiary care center, in which biofeedback training with EMG was performed in patients with suspicious dyssynergic defecation and did not improve despite continuous treatment with laxatives for 1-3 months or relapsed after tapering of laxatives. As a result, not all of the BET results could be compared with EMG during biofeedback training and this could lead to another selection bias. However, it was judged that the selection bias was minimized, since there was no statistically significant difference between the EMG group and Non EMG group in BET and ARM results, as above mentioned. Second, other diagnostic tests that might be helpful to diagnose dyssynergic defecation, such as defecography or colon transit times, were not performed. This was because of patients' preference and poor accessibility to those exams. Defecography is useful in identifying anatomical abnormalities, such as paradoxical contraction of the puborectalis muscles. ${ }^{25,26}$ However, the technique of defecography is incompletely standardized and has limited reproducibility in terms of anorectal angle measurements. ${ }^{27}$ Furthermore, there were risks of X-ray exposure and barium impaction, even though these risks are minimal. ${ }^{28}$

In conclusion, sensitivity of BET was at most $71.4 \%$ and NPV of BET was less than $15 \%$ in predicting paradoxical anal contraction or inadequate propulsive force when estimated from ARM or EMG during biofeedback training irrespective of BET criteria. BET seems to have a limitation as both a screening test for dyssynergic defecation and a simple assessment to rule out the necessity of biofeedback training.

\section{Financial support: None.}

\section{Conflicts of interest: None.}

Author contributions: Kyoung Sup Hong planned the study, designed the protocol, and contributed to the screening and pe- 
riodic visits of the patients; Joo Sung Kim and Hyun Chae Jung contributed to the screening and periodic visits of the patients; Jooyoung Lee analyzed the data; Kyoung Sup Hong and Jooyoung Lee contributed to the writing of the manuscript; Kyoung Sup Hong, Joo Sung Kim, and Hyun Chae Jung reviewed and edited the final manuscript; and all authors reviewed and approved the final manuscript.

\section{References}

1. Bharucha AE, Wald A, Enck P, Rao S. Functional anorectal disorders. Gastroenterology 2006;130:1510-1518.

2. Rao SS, Tuteja AK, Vellema T, Kempf J, Stessman M. Dyssynergic defecation: demographics, symptoms, stool patterns, and quality of life. J Clin Gastroenterol 2004;38:680-685.

3. Rao SS, Valestin J, Brown CK, Zimmerman B, Schulze K. Long-term efficacy of biofeedback therapy for dyssynergic defecation: randomized controlled trial. Am J Gastroenterol 2010;105:890-896.

4. Rao SS, Mudipalli RS, Stessman M, Zimmerman B. Investigation of the utility of colorectal function tests and Rome II criteria in dyssynergic defecation (Anismus). Neurogastroenterol Motil 2004;16:589-596.

5. Rao SS, Welcher KD, Leistikow JS. Obstructive defecation: a failure of rectoanal coordination. Am J Gastroenterol 1998;93:1042-1050.

6. Fleshman JW, Dreznik Z, Cohen E, Fry RD, Kodner IJ. Balloon expulsion test facilitates diagnosis of pelvic floor outlet obstruction due to nonrelaxing puborectalis muscle. Dis Colon Rectum 1992;35:1019-1025.

7. Minguez M, Herreros B, Sanchiz V, et al. Predictive value of the balloon expulsion test for excluding the diagnosis of pelvic floor dyssynergia in constipation. Gastroenterology 2004;126:57-62.

8. Rao SS, Meduri K. What is necessary to diagnose constipation? Best Pract Res Clin Gastroenterol 2011;25:127-140.

9. Rao SS. Constipation: evaluation and treatment of colonic and anorectal motility disorders. Gastrointest Endosc Clin N Am 2009;19:117-139, vii.

10. Mertz H, Naliboff B, Mayer E. Physiology of refractory chronic constipation. Am J Gastroenterol 1999;94:609-615.

11. Patcharatrakul T, Gonlachanvit S. Outcome of biofeedback therapy in dyssynergic defecation patients with and without irritable bowel syndrome. J Clin Gastroenterol 2011;45:593-598.

12. Rao SS. Advances in diagnostic assessment of fecal incontinence and dyssynergic defecation. Clin Gastroenterol Hepatol 2010;8:910-919.
13. Rao SS, Rattanakovit K, Patcharatrakul T. Diagnosis and management of chronic constipation in adults. Nat Rev Gastroenterol Hepatol 2016;13:295-305.

14. Rao SS, Patcharatrakul T. Diagnosis and treatment of dyssynergic defecation. J Neurogastroenterol Motil 2016;22:423-435.

15. Remes-Troche JM, Rao SS. Diagnostic testing in patients with chronic constipation. Curr Gastroenterol Rep 2006;8:416-424.

16. Lee BE, Kim GH. How to perform and interpret balloon expulsion test. J Neurogastroenterol Motil 2014;20:407-409.

17. Rao SS, Hatfield R, Soffer E, Rao S, Beaty J, Conklin JL. Manometric tests of anorectal function in healthy adults. Am J Gastroenterol 1999;94:773-783.

18. Dedeli O, Turan I, Ozturk R, Bor S. Normative values of the balloon expulsion test in healthy adults. Turk J Gastroenterol 2007;18:177-181.

19. Read NW, Abouzekry L, Read MG, Howell P, Ottewell D, Donnelly TC. Anorectal function in elderly patients with fecal impaction. Gastroenterology 1985;89:959-966.

20. Rao SS; American College of Gastroenterology Practice Parameters Committee. Diagnosis and management of fecal incontinence. American College of Gastroenterology Practice Parameters Committee. Am J Gastroenterol 2004;99:1585-1604.

21. Raza N, Bielefeldt K. Discriminative value of anorectal manometry in clinical practice. Dig Dis Sci 2009;54:2503-2511.

22. Rao SS, Ozturk R, Stessman M. Investigation of the pathophysiology of fecal seepage. Am J Gastroenterol 2004;99:2204-2209.

23. Chiarioni G, Kim SM, Vantini I, Whitehead WE. Validation of the balloon evacuation test: reproducibility and agreement with findings from anorectal manometry and electromyography. Clin Gastroenterol Hepatol 2014;12:2049-2054

24. Rao SS, Kavlock R, Rao S. Influence of body position and stool characteristics on defecation in humans. Am J Gastroenterol 2006;101:27902796.

25. Kuijpers HC, Bleijenberg G, de Morree $H$. The spastic pelvic floor syndrome. Large bowel outlet obstruction caused by pelvic floor dysfunction: a radiological study. Int J Colorectal Dis 1986;1:44-48.

26. Shin JE, Jung HK, Lee TH, et al. Guidelines for the diagnosis and treatment of chronic functional constipation in Korea, 2015 revised edition. J Neurogastroenterol Motil 2016;22:383-411.

27. Bharucha AE. Update of tests of colon and rectal structure and function. J Clin Gastroenterol 2006;40:96-103.

28. Rao SS, Camilleri M, Hasler WL, et al. Evaluation of gastrointestinal transit in clinical practice: position paper of the American and European Neurogastroenterology and Motility Societies. Neurogastroenterol Motil 2011;23:8-23. 